\title{
Working Across Borders: the Social and Policy Implications of Aging in the Americas
}

\author{
Fernando M. Torres-Gil • Eun Ha Suh • \\ Jacqueline Angel
}

Published online: 27 July 2013

(C) Springer Science+Business Media New York 2013

In this essay we provide a context for examining the complex issues of aging facing the Americas, particularly the United States and Mexico. The aging populations in the United States, Mexico, Central and South America raise the prospects of enhanced bilateral partnerships in gerontology and geriatrics. This work illustrates the ongoing evolution of paradigms, assumptions and theoretical frameworks that overlay the multidisciplinary and multi-faceted nature of gerontology and geriatrics within Latino, ethnic and racial groups.

While the general public is only recently developing an interest in issues of cultural diversity and aging, current scholarship describing the demographics of the emerging Hispanic population continues to mature. It is helpful to illustrate the evolution of "Hispanic Aging" over the last 40 years. By doing so, it creates a solid foundation for the research and policy analysis which describe how aging impacts Latinos in the U.S., Mexico and Latin America, as well as how diversity issues for Latinos influence demographic changes in those countries. This paper provides an introduction to the articles in this special volume and, we hope, bridges the issues of aging and diversity. It will also draw attention to issues facing aging populations nationally and globally. ${ }^{1}$

\footnotetext{
${ }^{1}$ This special issue comes from revised papers and connected work presented at the 2012 International Conference on Aging in the Americas meeting National, International, and Comparative Studies of Hispanic Aging and Related Methodological Challenges at the University of Southern California. The Co-organizers of the workshop were Mark Hayward, Kyriakos Markides, and William Vega.

This special issue comes from revised papers and related work presented at the 2012 International Conference on Aging in the Americas at the University of Southern California, Co-organized by Mark Hayward, Kyriakos Markides, and William Vega.
}

F. M. Torres-Gil $(\bowtie) \cdot$ E. H. Suh

University of California, Los Angeles, CA, USA

e-mail: torres@publicaffairs.ucla.edu

E. H. Suh

e-mail: eunhasuh@gmail.co

J. Angel

University of Texas at Austin, Austin, TX, USA

e-mail: jangel@austin.utexas.edu 


\section{The Evolution of a Sub-Discipline: Aging in Latino Communities Become Mainstream Concerns}

Over the last six decades, with the worldwide rapid growth of the aging population, gerontology and geriatrics disciplines have shifted from the sole purview of academics to conventional areas of public concern and interest. Gerontology practitioners and academics take satisfaction that their research and policy analysis and studies have received an additional measure of recognition and public policy. It is particularly relevant since it is predicted that by 2050, for the first time in United States history, the number of individuals aged 60 years and older may exceed the number of children aged 0 to 14 years. Persistent media attention to the political reality of reaching out to serve the needs of older voters; the potential effects of government entitlement reform (e.g., the sustainability of Medicare and Social Security) and the physical and psychological concerns of the aging population (e.g., aging-related diseases and affordable elder care) predicts that gerontology and geriatric scholars and practitioners will be the leaders in applying their formidable knowledge to these pressing concerns.

Issues of diversity, race, ethnicity and immigration have evolved at a more deliberate pace with much less visibility and attention. However, recent funding support and interest from academia and private industry has increased for research focusing on aging minorities. Additional work is required in aging relative to U.S. minority groups, but fortunately there is no longer a need to justify the interest or applicability. Thus, we now find ourselves at a new frontier in aging: the emergence of Latinos as a demographic, political and social force in the United States and the rapid aging of Latin America, particularly Mexico. Questions arise to the juxtaposition in these developing trends: how does one inform the other; how may the scholarship of the aging U.S. Latino population (including Mexican immigrants to the U.S., Mexican migrants who return to their homeland after retirement, as well as Latinos in their host country) be applicable to the worldwide phenomenon of all aging populations?

This Journal of Cross-Cultural Gerontology issue examines a variety of topics related to these questions, including the social and functional status of the elderly in Mexico, the economic needs of Latino elders in the U.S., chronic disease prevention in Latin America; migration and its impact on physical and mental health, and continuing debates about the "Hispanic paradox." Collectively, these articles reach across national boundaries and utilize the emerging U.S. Hispanic population as a topical anchor in order to highlight a litany of questions related to aging and Hispanics. This work is only a start. Additional study is needed to create a comprehensive intellectual foundation for understanding the myriad dynamics of aging and its demographic intersections across all Latino populations in the Americas. With this beginning, researchers and policy analysts can chart the implications, consequences and policy responses of the Latinos in the United States and hemisphere as a whole by addressing and recognizing the demographic changes in their populations. Indeed, there is a clear economic interdependence between the United States, Mexico, and Central American populations given the massive immigrations from those countries.

In outlining these issues, it is instructive to use two time frames in order to set goals for research and policy outcomes: 2030 and 2050. By 2030, Latinos will be the largest minority group in the U.S., surpassing African Americans. By 2050, the majority of the United States population will be comprised of citizens with ethnic heritages (Hispanic; Black and Asian) and surpass the Anglo-Saxon population, thus irrevocably changing the nation's demographic identity. How will these benchmarks illuminate the growing diversity and aging of the U.S., as well as the aging of Latin America? And how may Hispanics in the U.S., and Latinos throughout Latin America, serve as the case study for the future of aging in the U.S., 
Mexico and throughout the Americas? It is our goal that this Journal will assist in framing these issues for social scholars conducting research in this vital area.

\section{The Evolution of an Idea and a Sub-Discipline: Hispanic Aging}

Scholarly interest surrounding the phenomenon of aging in diverse communities is a relatively recent academic development; research in this area only emerged over the last forty years. Fernando M. Torres-Gil, the principal scholar who first explored this research area, published the first bibliography on "Hispanic Aging" while a young Brandeis University graduate student (Torres-Gil 1972). Subsequently, the field has extensively widened to include many other researchers intensely interested in this field; first largely descriptive and advocacy based (McNeely and Colon 1983). The body of literature subsequently grew to include African Americans, Asians and Pacific Islanders and Native Americans, again largely descriptive and focused on the social and cultural identifiers of those groups (Gelfand and Barresi 1987; Bass et al. 1989). Vern Bengtson at the University of Southern California led the first comparative research projects funded by the National Science Foundation (Bengtson et al. 1977). This pioneer approach to diversity and aging provided the first scholarly basis of informational studies to describe the cultural uniqueness of African Americans, Asians and Pacific Islanders and Native Americans in Southern California (Bengtson et al. 1977). Others, including Percil Stanford (The Institute on Minority Aging 1978) at San Diego State University, contributed to these efforts to raise interest in minority geriatric studies and gerontology. All these early studies were seminal in solidifying the academic credibility and foundation of the Minority Aging research field.

Current demographic developments create a strong case for studying minority aging in the United States. The population growth of the minority elderly (aged 65 and over) as a percentage of the overall elderly population is projected to increase rapidly: between 2010 and 2050, the Asian elderly population will increase from $1.3 \%$ to $7.5 \%$; for African Americans, from $3.4 \%$ to $10.5 \%$; and for the Hispanic elderly from $3.4 \%$ to $17.5 \%$ (Angel et al. 2012). Through much of the 1980s and 1990s, however, minority aging research was secondary to traditional research in gerontology and geriatrics, whose research focused on aging in the Anglo Saxon population.

However, as the U.S. population demographic continues to change due to immigration, issues addressing the confluence of diversity and aging become increasingly salient and an important public policy area. New research and longitudinal studies now lend considerable seriousness to these topical areas. ${ }^{2}$ From the first 1970s National Science Foundation (NSF) study, there now, in 2013, exist a multitude of more elaborate longitudinal studies and data sets. For example, the San Antonio Longitudinal Study of Aging (SALSA) provides a communitybased assessment of the disablement process among Mexican Americans and European Americans in San Antonio, Texas. This data set is unique as it includes detailed information on socio-cultural characteristics (e.g. socioeconomic status, acculturation, assimilation) which inform the disability circumstances (e.g. diabetes) facing Mexican Americans. Perhaps the most prominent effort is an ongoing longitudinal study of the health of older Mexicans Americans from five Southwestern states: Arizona, California, Colorado, New Mexico and Texas. The Hispanic Established Population for the Epidemiologic Study of the Elderly (H-EPESE) was funded by the National Institute on Aging (NIA) in 1992 and has generated extensive new peerreviewed research (over 180 publications) on the prevalence and incidence of chronic conditions, mental health, disability, mortality, cognitive function and medical care utilization. These

\footnotetext{
${ }^{2}$ The Hispanic Established Populations for the Epidemiologic Studies of the Elderly (Hispanic- EPESE).
} 
two studies demonstrate advancement in the research, scholarly and intellectual understanding of aging among certain segments of Latinos.

With this new foundation of research data, new policy questions that identify these social issues will continue to frame larger debates around the demographic changes in the Americas. This represents the next frontier of research and policy analysis: identifying the new policy projects that can assist nations experiencing rapid aging within their increasingly diverse populations.

These new questions include: what might this next stage of research include? How might issues of demographics and diversity become part of greater policy debates in the U.S. and Latin America? Examples such as:

- Understanding issues of fertility and birth rate fluctuations across the Americas;

- Examining the varied nation-state governmental responses;

- Understanding the confluence of cultural, social and behavioral conditions associated with aging;

- Funding, adapting and applying new public surveys and longitudinal studies;

- Uncovering the potential for advocacy, leadership and the politics of aging in the Americas

An effective place to begin is to examine the two countries most intertwined in their demographic destiny: Mexico and the United States.

\section{Mexico and the United States: Strange Bedfellows}

Due to the shared border between Mexico and the United States, a multitude of challenges permeate all of their interactions: access to water; border control and sovereignty; violent crime; multibillion dollar trade; national security; legal and illegal immigration. Newly added to this are the demographic challenges of aging and longevity and how the respective governments respond to their aging populations. Indisputably, the United States has historically benefitted economically from its open and free immigration policy, unparalleled in the world. Hundreds of thousands of Mexican immigrants annually enter the United States, legally and illegally, driving the U.S. economy to become the largest in the world due, in large part, to the skills of its enterprising young immigrants. Despite the debate surrounding immigration policy, the United States has benefited from the acculturation of legal and undocumented persons to U.S. civic and political institutions, as well as the unquestionable military, cultural, and political contributions of Hispanics to the United States. The benefits of Mexico's close alignment to the United States cannot be underscored, as well: the U.S. is Mexico's largest trading partner with the North American Free Trade Agreement (NAFTA) helping to fuel Mexico's national economy; a non-militarized border which saves billions of dollars in national security expenditures for both countries, and the rising Mexican middleclass which leverages the economic, educational, technological and geographic opportunities from the United States.

Accordingly, issues of aging also become a bilateral phenomenon. According to the Fox Institute (Aguila et al. 2011), Mexico is no longer a youthful nation; it is experiencing the same world-wide aging trends. Its replacement rate was approximately 2.1 in 2012 (Central Intelligence Agency 2012), and it is trending downwards. Driving this phenomenon is the continued migration of Mexican youth to the United States. As Mexico continues to experience a rise in the elderly population, it will draw on the productivity and tax revenues of a larger working-age population with fewer dependent children, and be able to increasingly invest in building out its national infrastructure (e.g., improved highways, rural access, etc.). 
Additionally, an aging population also decreases generalized crime rates. Issues of political corruption, a violent fueled drug war, and civic instability must be addressed, however, for a sustainable future for all Mexican citizens.

In a prescient article connecting fertility and immigration, Last (2013) addresses the connection with aging and between the U.S. and Mexico. In 1970, Mexico's fertility rate was 6.72; today, with a fertility rate of 2.1 (a $70 \%$ decline in two generations), that rate continues to decrease. This substantially contributes (alongside the economic recession in the U.S. and greater economic opportunities in Mexico) to a potential net zero immigration rate from Mexico. There will be a profound change in the demographic relationships between these two countries. Implications abound for debates around immigration, bilateral relationships, economic ties and perceptions by each nation of its political and policy agendas. Yet, unlike other highly developed countries facing this phenomenon (e.g. China, Korea, Russia), Mexico's population is rapidly aging faster than its ability to increase its economic wealth (Rand 2012). Moreover, Mexico has an absence of entitlement laws and public benefit programs found in the United States, (e.g. Older Americans Act; Social Security, Medicare, American with Disability Act) and can no longer rely on traditional care, such as utilizing the resources of a large family. Less than one half of the working-age population contributes to a retirement program. (Hernández and Vernon 2011). Such inadequacy in retirement plans and social welfare programs compromise feelings of security among the young, elderly and impoverished in Mexico, and has consequences beyond the more traditional U.S.-Mexico border conflicts (Frenk and Gómez-Dantés 2007)). Elders in Mexico without financial and familial support will face greater vulnerability with increased life expectancy. Young and middle-aged persons will be forced to meet their subsistence needs with insufficient retirement resources.

Fortunately, Mexico does have a variety of government funded programs that provide health care and social support, yet these programs are not historically nor specifically designed and funded for elder care. In recent years, Mexico's national government has elevated issues of aging on the national agenda and there is a developing scholarship and practitioner base of gerontologists and geriatricians. A growing recognition of the new demographic reality is emerging, and Mexico is responding.

Ironically, many U.S. citizens embrace Mexico due to its affordable real estate for retirement living. An estimated one million U.S. expatriates live in retiree enclaves such as Chapala, San Miguel de Allende, Guanajuato and other locales where U.S. retirement incomes have a comparably strong purchasing power, and whose environments offer an affordable yet comfortable quality of life (Migration Policy Institute 2006). Concurrently, however, the United States continues its debate on immigration policies and boarder control. Recent data (Passel et al. 2012), indicates immigration, legal and illegal, from Mexico to the United States has generally decreased and it remains uncertain whether the U.S. will continue to experience a historical flow of Mexican immigrants. Regardless, there still exists a substantial pool of undocumented Mexicans eager to become U.S. citizens (Terrazas 2011). Others support this finding, particularly in light of the effect of the global recession on economic incorporation (Terrazas 2011).

While the United States debates the benefits and detriments of immigration policies, it also confronts the undeniable reality of its own reduced fertility rates of non-Hispanic white Americans. In order to sustain its economic growth, the U.S. requires a constant inflow of immigrants to pay taxes and fund its government programs. With recent developments indicating that even Hispanic-Americans may be reducing their fertility rates, the United States may have to address what Japan, Korea, Western Europe and Russia have experienced in recent decades: a national program to encourage increased birth rates, or an increased recruitment of immigrant workers to bolster their declining populations. 
Thus, the growing interdependence of the United States and Mexico and the role of demography and aging illustrate a potential bridge to a new partnership. The conference series on "Aging in the Americas" is an excellent opportunity to gather practitioners and policy analysts to identify the needs and concerns of aging populations in the U.S., Mexico and Latin America, and to forge partnerships of mutual collaboration.

Given these developments, what actions may be taken to advance a more robust partnership? What are the parameters by which researchers, intellectuals, advocates and policy leaders can develop strategic agendas? And what might surface as obstacles to the pursuit of a more inclusive and effective collaboration between the U.S., Mexico and Latin America given these new demographic realities? Noted scholars, Dr. Julio Frenk and Dr. Octavio Gómez Dantés remind us that "Aging in the Americas" and geriatric health policy serves as a focus given its universal appeal across nations and human aspirations (Angel and Whitfield 2007).

\section{The Future of Aging in the Americas: A New Agenda}

The future of aging and demographics in the United States, Mexico and Latin America is such that partnerships and collaboration now become necessary strategies if the Americas are to respond to the needs of their elders, and if aging is to become an advantage, not a detriment. This will not be an easy undertaking. Longevity, growing elder populations, and declining rates of fertility are likely to engender more difficulties than optimism.

The current economic climate in the United States may best illustrate the critical nature of this issue. At present, the U.S. is engaged in contentious political debates about the nation's fiscal and economic future. Annual federal deficits (approximately \$1.5 trillion), an escalating national debt (approximately $\$ 16$ trillion) and a voting public skeptical about raising taxes have forced politicians and national leaders to focus on reducing spending for entitlement programs, whose funding requirements represent a significant percentage of the national budget. As 2013 and 2014 progresses, it is likely the three major entitlement programs that provide a safety net for the elderly in the United States - Medicare, Medicaid and Social Security — may be detrimentally affected. Medicare and Medicaid, the two national health care programs for the elderly and the poor, face potential insolvency. Social Security, although in relatively good fiscal shape for the next several decades, faces the possibility of privatization. Should substantial restructuring occur with these three national programs, the nation's aging public namely, the "Baby Boomer" generations (National Research Council 2012) may experience greater financial and social insecurity. Concurrently, the United States government and its citizens increasingly recognize that demographics will profoundly reshape the social and cultural character of this country. With the U.S. population of older persons expected to double by 2030 , and with ethnic populations representing the majority of its citizens, policy makers must be effectively prepared to address these societal shifts. One recent example of these shifts is illustrated by the popular reelection of the country's first African-American president in 2012, as well as the realization that the Hispanic, Asian and young voters were new, crucial factors in driving successful electoral political campaigns. These two outcomes have propelled both political parties-Democrats and Republicans - to seriously consider immigration reform legislation in the United States, and the possible legal status for thousands of young undocumented workers brought to this country as children (through, for example, the DREAM Act). Any forward progress on these fronts will be optimistic developments.

Another potentially significant outcome of the "Aging in the Americas" conferences was the recognition that in an aging society where the majority of the elderly will be white, non-Hispanic 
and English speaking, the rapid growth of a young, largely Hispanic and Mexican immigrant population will become of significant service to this elder population. These young immigrants will become taxpayers, with the ability to subsidize the government entitlement programs such as Medicare, Medicaid and Social Security. They may also occupy the long-term caregiving workforce that will be required to serve and support these aging populations. This may be a start of productive partnerships between the U.S., Mexico and Latin America, as this scenario illustrates the mutual benefits these changing demographics may have on the aging in the Americas.

Mexico, despite having one of world's largest economies as a newly industrialized country, continues to face challenges of a developing nation. Significant media attention continues to highlight Mexico's entrenched and systemic political and judicial corruption; continued drug violence and its government's inability to reduce the large economic disparity between the extremely impoverished and the extremely rich. Mexico, however, continues to make impressive progress in expanding universal education; creating a large middle class, reducing general levels of poverty and continued government investment in its growing information technology sector. However, despite these hopeful signs, it is clear that many of its civic goals are yet to be achieved.

In closing, the demographic links between the two nations produce an added advantage: the capacity for collaboration in order to address similar challenges presented by their respective aging populations. This represents a unique opportunity for gerontologists and geriatricians on both sides of the border to inform and strengthen their policies and political institutions.

\section{References}

Aguila, E., Diaz, C., Fu, M. M., Kapteyn, A., \& Pierson, A. (2011). Living longer in Mexico: Income security and health. Santa Monica: RAND Corporation.

Angel, J., Torres-Gil, F., \& Markides, K. (Eds.). (2012). Aging, health and longevity in the Mexican-origin population. Springer Publishing Company.

Angel, J. L., \& Whitfield, K. E. (2007). The health of aging Hispanics: The Mexican-origin population. New York: Springer Science.

Bass, S., Kutza, E., \& Torres-Gil, F. (1989). Diversity in aging: Challenges facing planners and policymakers in the 1990s. Glenview: Scott, Foresman and Co.

Bengtson, V. L., Grigsby, E., Corry, E. M., \& Hruby, M. (1977). Relating academic research to community concerns: a case study in collaborative effort. Journal of Social Issues, 33(4), 75-92.

Central Intelligence Agency (2012). Total Fertility Rate. The World Fact Book. Washington, DC. Retrieved from https://www.cia.gov/library/publications/the-world-factbook/geos/mx.html.

Frenk, J., \& Gómez-Dantés, O. (2007). In J. L. Angel \& K. E. Whitfield (Eds.), Globalization and health: Risks and opportunities for the Mexico-U.S. Border (pp. 280-288) in The health of aging Hispanics: The Mexican-origin population. New York: Springer Science.

Gelfand, D., \& Barresi, C. (Eds.). (1987). Ethnic dimensions of aging. New York: Springer Publishing Company.

Hernández, A., and Vernon, A. (2011). The Reformed Mexican Social Security System: 15 years of experience. Retrieved from http://www.actuaries.org/HongKong2012/Papers/MBR5_Hernandez.pdf.

Institute on Minority Aging, 4th, San Diego, Calif., 1977. (1978). Comprehensive service delivery systems for the minority aged. Stanford, E.P. (Ed.). Center on Aging, School of Social Work, San Diego State Univ.: distributor, Campanile Press.

Last, J. (2013). Fertility and Immigration. Los Angeles Times, p. A19.

McNeely, R., \& Colon, J. (1983). Aging in minority groups. Beverly Hills: Sage Publications.

Migration and Policy Institute (2006). America's Emigrants: US Retirement Migration to Mexico and Panama. Migration Policy Institute and New Global Initiatives.

National Research Council. (2012). Aging and the macroeconomy: Long-term implications of an older population. Washington, DC: The National Academies Press. 
Passel, J. S., D’Vera Cohn, G. B. A., \& Gonzalez-Barrera, A. (2012). Net Migration from Mexico Falls to Zero-and Perhaps Less. Pew Research Center.

Rand Corporation (2012). Mexicans Work and Work, But Will Retirement Work for Them? Santa Monica, CA. http://www.rand.org/pubs/periodicals/rand-review/issues/2012/spring/window.html.

Terrazas, A. (2011). The economic integration of immigrants in the United States: Long- and short-term perspectives. Migration Policy Institute.

Torres-Gil, F. (1972) Los Ancianos de la Raza: A Beginning Framework for Research, Analysis and Policy. Unpublished Master's thesis, Brandeis University. 